\title{
Monte Carlo Ray Tracing Based Adjacency Effect and Nonlinear Mixture Pixel Model for Remote Sensing Satellite Imagery Data Analysis
}

\author{
Kohei Arai ${ }^{1}$ \\ Graduate School of Science and Engineering \\ Saga University \\ Saga City, Japan
}

\begin{abstract}
Monte Carlo Ray Tracing: MCRT based adjacency effect and nonlinear mixture pixel model is proposed for remote sensing satellite imagery data analysis. Through simulation and actual visible to near infrared radiometer onboard spaceborne data utilizing experiment, the proposed model is confirmed and validated. Therefore, influences due to adjacency effect and nonlinearity of mixed pixel can be taken into account in the remote sensing satellite imagery data analysis.
\end{abstract}

Keywords-adjucency effect; nonlinear mixed pixel model; Monte Carlo method; Ray tracing method

\section{INTRODUCTION}

All land pixels in remote sensing imagery are essentially mixed pixels that consist of multiple ground cover materials. Currently, there are two types of models aiming to untangle these contributions: linear and non-linear mixture models. The linear mixture models assume negligible interactions among distinct ground cover materials while the nonlinear mixture models assume that incident solar radiation is scattered within the scene itself and that these interaction events may involve several types of ground cover materials. R.Singer and T.B.McCord (1979) [1], B.Hapke (1981) [2] and R.N.Clark and T.I.Roush (1984) [3] proposed linear mixture models while R.Singer (1974) [4], B.Nash and J.Conel (1974) [5] proposed nonlinear mixture models for the mixed pixels containing different mineral resources. Meanwhile, C.C.Borel and S.A.Gerst (1994) [6] proposed another nonlinear mixture model for vegetated areas. These nonlinear mixture pixel models, however, did not take into consideration the influence of topographic features nor the influence of multiple scattering in the atmosphere.

A nonlinear mixture model for the interpretation of mixed pixels in remote sensing satellite images is proposed. The proposed model is a Monte Carlo ray-tracing model that takes into account interactions among the ground cover materials (multiple reflections among the materials on the surface). The proposed model also takes into account topographic features (slope) of the ground surface. As an example, Top of the Atmosphere: TOA radiance of mixed pixels of forested areas which are composed of grasses and trees are simulated with the proposed model and compared to actual remote sensing satellite data of ASTER/VNIR over these forested areas. It was found that the influence due to multiple scattering interactions between trees depends on the tree distance and ranges from 8 to $10 \%$. It is also found that the proposed model is useful to interpret mixed pixels. Namely, it is suggested that actual reflectance of the trees is higher than apparent reflectance that is calculated with the satellite data. Also it is suggested that it is possible to estimate forest parameters such as tree distance, tree shape.

This paper proposes a nonlinear mixed pixel model that takes into account topographic features of the surface and multiple scattering in the atmosphere. Furthermore, the proposed nonlinear mixed pixel model takes into account interactions among ground cover materials (trees) separated by different distances and having different shapes (crowns). Since multiple scattering interactions in $3 \mathrm{D}$ media are not so easy to solve using the radiative transfer equation, the proposed mixture model is based on Monte Carlo Ray-Tracing: MCRT.

Section 2 describes the proposed nonlinear mixed pixel model together with details of the MCRT algorithm. Section 3 presents experimental results showing the influence of multiple scattering interactions between trees, the shape of the trees, the slope of the terrain, and the atmospheric optical depth. Finally, the model derived Top-of-the-Atmosphere: TOA radiance over forested area is compared to actual remote sensing satellite observations by the visible and near-infrared radiometer, ASTER/VNIR: Advanced Spaceborne spectralradiometer for Thermal Emission and Reflection / Visible and Near Infrared Radiometer onboard Terra satellite data.

\section{PROPOSED MODEL}

\section{A. The Monte Carlo Ray-Tracing:MCRT Simulation Model}

Nonlinear mixture model and brief description of Monte Carlo Ray-Tracing model: MCRT. Nonlinear mixing model proposed here is composed with more than two ground cover materials and is based on the MCRT model. In order to take into account the geographical feature, slope of the ground surface can be changed. Also any ground cover materials can be set for the ground surface together with different shape of ground cover materials. The simulation with MCRT model is called MCRT Simulation, MCRTS (Arai, 2005) [7]. In MCRTS, 50 by 50 by $50 \mathrm{~km}$ of simulation cell size is assumed. The ground surface is composed with two planes, surface A and $\mathrm{B}$, with the different slopes, aand $\beta$ and with surface reflectance, $\Gamma_{\mathrm{A}}$ and $\Gamma_{\mathrm{B}}$ as is shown in Figure 1. a and b show IFOV on the ground for the surface $A$ and $B$. 


\section{TOA.Rad.}

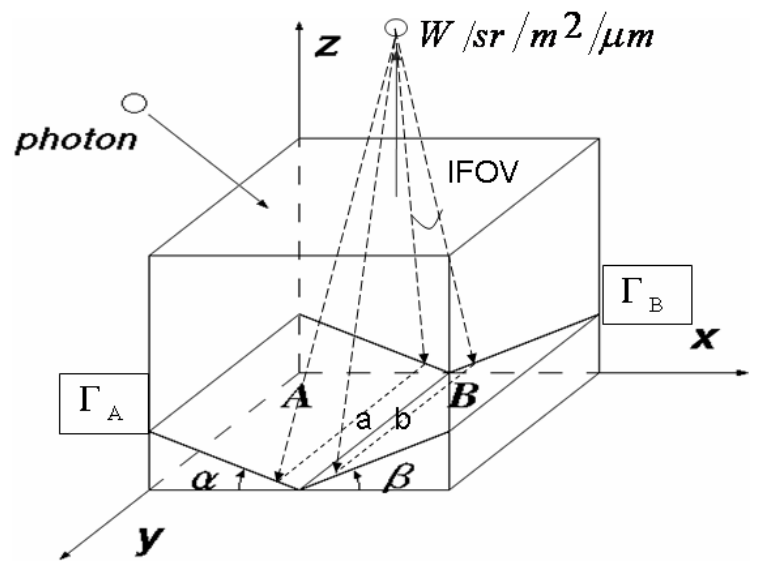

Fig. 1. Nonlinear mixed pixel model based on Monte Carlo Ray-Tracing Simulation model with 50x50x50km cell and two ground surfaces (The pixels situated along with border between two surface are mixed pixels).

A photon is put in the simulation cell from the top of the cell with the incidence angle that depends on the specified solar zenith angle. The position of which the photon is put in is changed by time by time in accordance with the uniformly distributed random numbers.

Depending on the optical depth of the atmosphere, free travel length $L$ of photon is determined as follows,

$$
\begin{aligned}
& L=-L_{0} \log (\text { Rnd }) \\
& L_{0}=\frac{h}{\tau_{\text {all }}}
\end{aligned}
$$

where $L_{0}$ is called free travel length, denoting the average distance of interaction of a photon from one position to another. Rnd is uniformly distributed random numbers ranges from 0 to $1 . h$ denotes the physical height of the atmosphere $\left(50 \mathrm{~km}\right.$ in this case) while $\tau_{\text {all }}$ denotes the optical depth of the atmosphere which is determined as follows,

$\tau_{\text {all }}=\tau_{\text {aero }}+\tau_{\text {mol }}$

where the subscript aero is associated with aerosols while mol with molecules. Here, it is assumed that atmosphere consists of aerosols and air molecules. Because the wavelength in concern ranges from 450 to $1050 \mathrm{~nm}$ so that optical depth of ozone and water vapors are assumed to be negligible except $936 \mathrm{~nm}$ of water vapor absorption band. A small absorption due to ozone is situated from 500 to $650 \mathrm{~nm}$ around.

The photon meets aerosol particles or molecule when the photon travels in the atmosphere then scattering due to the aerosols or molecules occurs. The probability of the collision to the aerosols or molecules depends on their optical depths. If the endpoint of photon travel is in the atmosphere, the photon meets aerosol or molecule. The probability of the photon meets aerosol is $\tau_{\text {aero }} / \tau_{\text {all }}$ while that of the photon meets molecule is $\tau_{\text {mol }} / \tau_{\text {all }}$. In accordance with the phase function of aerosols or molecules, the photon is scattered. Strength of scattering as a function of scattering angle $\theta$ is determined by the phase function, $P(\theta)$, the Rayleigh for molecules, equation (4) and Heyney-Greestein function, equation (5) (it is just an approximation function of which the phase function is monotonically decreasing) for aerosols. Actual phase function can be determined with MODTRAN 4.0 of Mie code with the measured refractive index of aerosols through field experiments. By using uniformly distributed random numbers, scattering direction is determined. The phase function as $P(\theta)$, where $\theta$ is the angle between the incident direction and the scattering direction.

For molecules, the Rayleigh phase function is as follows,

$$
P(\theta)=(3 / 4)\left(1+\cos ^{2} \theta\right)
$$

While that for aerosols, we use the Heyney-Greenstein approximation function of the following,

$$
P(\theta)=\frac{1-g_{\lambda}^{2}}{\left(1+g_{\lambda}^{2}-2 g_{\lambda} \cos \theta\right)^{3 / 2}}
$$

Where $g_{\lambda}$ is the asymmetry factor of the aerosol phase function which depends on the wavelength of the radiation and the compositions, sizes, and the shapes of the aerosol particles.

In the calculation of TOA radiance, the number of photons, $N$ which comes out from the top of the atmosphere within the angle range which corresponds to the Instantaneous Field of View: IFOV of the sensor in concern is used thus the normalized TOA radiance, $\mathrm{Rad}$ is determined as follows,

$$
R a d=\frac{\mu_{0} \mu \Delta \mu}{2}\left(\frac{N}{N_{\text {total }}}\right)
$$

$$
\text { where } \mu_{0}=\cos \theta_{0}, \mu=\cos \theta, \theta_{0} \text { is the solar zenith }
$$
angle and $\theta$ is a viewing solid angle. $\Delta \mu$ is a view solid angle, i.e., FOV (field of view). $N_{\text {total }}$ is the number of photons which are put in the cell in total. If you multiply solar irradiance to Rad in unit of $(\mathrm{W} / \mathrm{m} 2 / \mathrm{str} / \mu \mathrm{m})$, then the TOA radiance in the same unit is calculated.

The input parameters are determined by field experimental data. They are (1) Material reflectance which is albedo of the entire ground cover material, (2) Background surface material reflectance, (3) Material-material distance, (4) Optical depth of aerosol and molecule, (5) Solar zenith and azimuth angles, (6) IFOV of the sensor, (7) Sensor direction (view zenith angle) and height. On the other hand, output parameters include TOA radiance and ten groups of photons. They are (1) Photons that are put in the atmosphere from the top of cell in total, (2) Photons that are come from the top of the cell within the range of IFOV, (3) Photons that are reflected by material, 
(4) Photons that are absorbed by material, (5) Photons that are reflected on the background, (6) Photons that are absorbed on the background, (7) Photons that are scattered by aerosols, (8) Photons that are absorbed by aerosols, (9) Photons that are scattered by molecules and (10) Photon that are absorbed by molecule. A photon equation must be formed, that is, the number of put-in-photons must be equal to the sum of comeout-photons which are come-out from the top of cell and the photons which are absorbed by aerosols and molecules, material and background. Each simulation has proved this equation.

From the results from the preliminary MCRTS with a plenty of input parameters, it is concluded that 700,000 of putin-photons would be enough for the MCRTS in many cases.

\section{B. Parameters and more detailed description of Monte Carlo ray tracing}

Wavelength for MCRTS can be set freely and is set the coverage from 450 to $1050 \mathrm{~nm}$ in this case. Solar azimuth and zenith angles can also be set freely and are set at 17 and 58 degrees, respectively in this case (those at Terra/ ASTER satellite over path time on December 152004 when the field campaign was conducted). Optical depth of molecule and aerosol are designated within a range from 0 to 0.5 for typical conditions. The actual phase function used in the MCRTS is shown in Figure 2. Mie phase function used for MCRTS is determined by using Mie code of MODTRAN 4.0 with the measured refractive index using skyradiometer, POM-I which allows measurements of direct, diffuse and aureole of solar irradiance in Saga city on December 152004.

The measured size distributions of aerosol as well as optical depths of total atmosphere, water vapor, molecule, total column ozone, and aerosol are shown in Figure 3 and 4, respectively. Size distribution shows bi-modal characteristics, one peak is situated at the $0.2 \mu \mathrm{m}$, while the other peak is situated at $1.2 \mu \mathrm{m}$. Junge distribution is assumed for simplifying calculation. The measured Junge parameter (3 in this case) is used for MCRTS. The test site is situated in the Saga city, Japan near by the Ariake Sea so that aerosol are mixed aerosol of relatively small particles of water soluble and comparatively large size of oceanic sea salt aerosols.

In the Figure 4, the measured optical depth of total atmosphere that measured with MicroTops-II (Optical depth specification: $340,500,675,870,1020 \mathrm{~nm}$ ) is shown with green colored cross marks. Also column ozone and water vapor are measured at the test site with MicroTops-II (Ozone and water vapor measurement specification). With the measured optical depth, solid lines of smooth characteristics of optical depth of total atmosphere, ozone and water vapor are calculated with MODTRAN 4.0 through a curve fitting. Optical depth of molecule can be calculated with measured atmospheric pressure and wavelength. Then optical depth of aerosol is estimated by subtracting optical depth of ozone, water vapor and molecule from that of total atmosphere.

$P(\theta)$

\section{Verification of Monte Carlo ray-tracing simulations}

The proposed MCRTS is validated with the MODTRAN 4.0 of atmospheric code that allows estimation of TOA radiance with the atmospheric and ground surface parameters. A flat Lambertian surface with reflectance of 0.2 (vegetated area) is assumed together with the Mid.-Latitude-Winter of the other default parameters. Optical depth of aerosol ranges from 0.1 to 0.5 . Meanwhile molecule optical depth is around 0.1 at $550 \mathrm{~nm}$, center wavelength of band 1 of ASTER/VNIR in accordance with atmospheric model of Mid.-Latitude-Winter of MODTRAN 4.0 while those of aerosol (refractive index $=1.44-0.005 \mathrm{i}$ which are estimated with the field campaign data which was conducted in Saga test site on December 15 2004) for optical depth of 0.1, 0.2, 0.3, 0.4, and 0.5 those are corresponding to the visible range of $70,30,20$, 15 and $13 \mathrm{~km}$, respectively. Table 1 shows the TOA radiance at $550 \mathrm{~nm}$ derived from MODTRAN 4.0 and those derived from MCRTS.

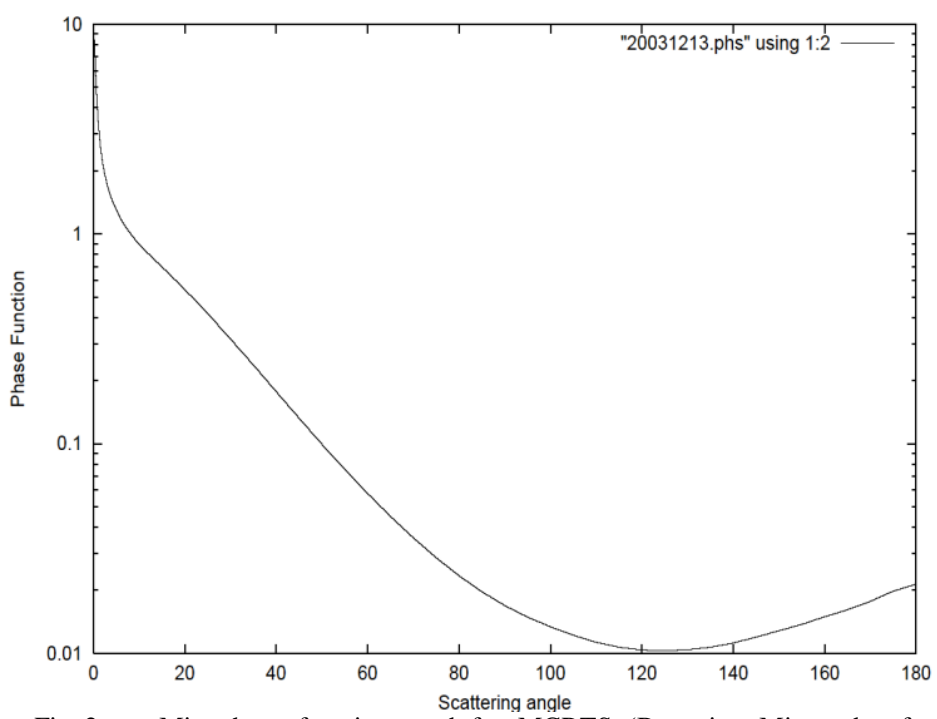

Fig. 2. Mie phase function used for MCRTS (By using Mie code of MODTRAN 4.0 with the measured refractive index using skyradiometer, POM-III in Saga city on December 152004.

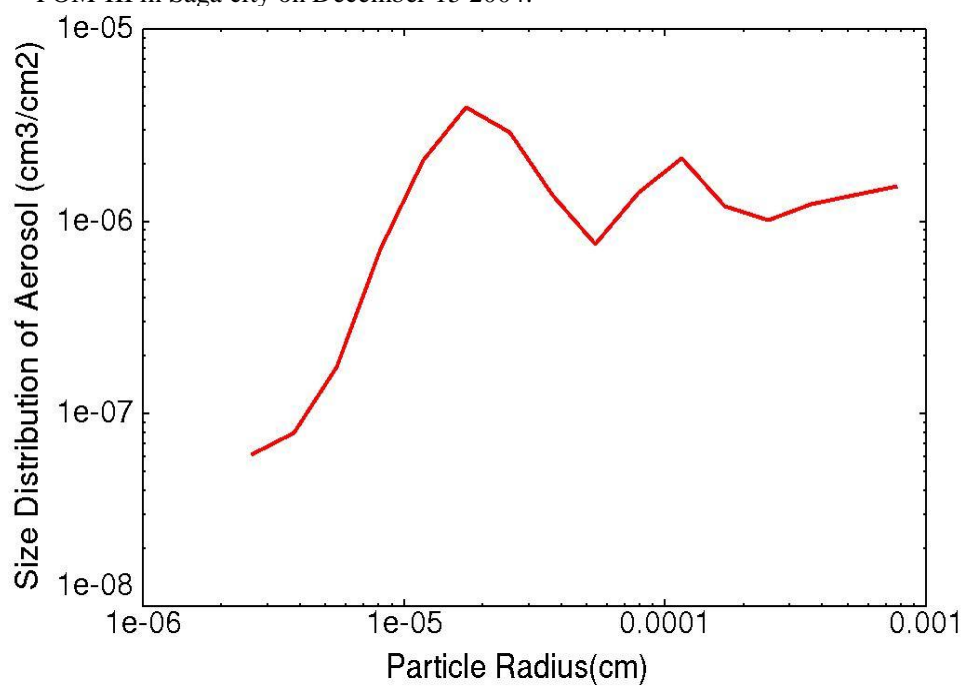

Fig. 3. Measured size distribution of aerosol at the Saga test site in Japan on December 152004. 


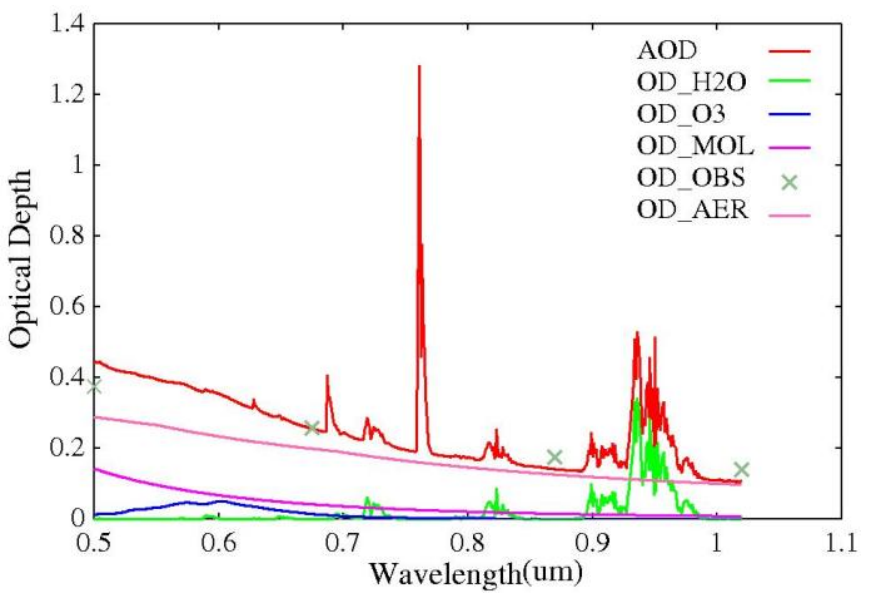

Fig. 4. Measured optical depths of total atmosphere (AOD), water vapor (OD_H2O), column ozone (OD_O3), molecule (OD_MOL), and aerosol (OD_AER) at Saga test site in Japan on Dec.15 2004. OD_OBS denotes observed optical depth.

On the other hand, molecule optical depth of the Mid.Latitude Winter of MODTRAN4.0 is 0.02 at $810 \mathrm{~nm}$, center wavelength of band 3 of ASTER/VNIR while aerosol optical depth of $0.1,0.2,0.3,0.4$ are corresponding to the visible range of 55, 25, 18 and $12 \mathrm{~km}$, respectively. Reflectance of the vegetation is assumed around 0.5 at $810 \mathrm{~nm}$. TOA radiance at $810 \mathrm{~nm}$ is shown in Table 2. In accordance with increasing of aerosol optical depth, TOA radiance is increased due to the fact that the path radiance is increased with increasing of aerosol optical depth in the $550 \mathrm{~nm}$ wavelength region while TOA radiance decreases in accordance with increasing of optical depth in the $810 \mathrm{~nm}$ because path radiance is rather small in comparison to that in the $550 \mathrm{~nm}$ region. In accordance with increasing of aerosol optical depth, TOA radiance is increased due to the fact that the path radiance is increased with increasing of aerosol optical depth in the 550 $\mathrm{nm}$ wavelength region while TOA radiance decreases in accordance with increasing of optical depth in the $810 \mathrm{~nm}$ because path radiance is rather small in comparison to that in the $550 \mathrm{~nm}$ region.

As the results from the comparisons with the typical atmospheric and surface conditions, the difference between both is within a range of $2 \%$. There are two systematic discrepancies between both. One is the TOA radiance derived from MODTRAN is greater than that from the proposed MCRTS. The other one is the difference depends on optical depth.

TABLE I. COMPARISON BETWEEN MCRTS AND MODTRAN DERIVED TOA RADIANCE AT ASTER/VNIR BAND 1(550NM)

\begin{tabular}{|c|c|c|c|c|c|}
\hline \multicolumn{2}{|c|}{ Optical Depth } & \multirow{2}{*}{$\begin{array}{l}\text { Visible } \\
\text { Range } \\
(\mathrm{km})\end{array}$} & \multicolumn{2}{|c|}{$\begin{array}{l}\text { TOA Radiance } \\
\left(\mathrm{W} / \mathrm{m}^{2} / \mathrm{str} / \mu \mathrm{m}\right)\end{array}$} & \multirow{2}{*}{$\begin{array}{l}\% \\
\text { difference } \\
\text { between } \\
\text { MCRTS } \\
\text { and } \\
\text { MODTRAN }\end{array}$} \\
\hline Molecule & Aerosol & & MCRTS & MODTRAN & \\
\hline 0.1 & 0.1 & 70 & 106.7 & 107.1 & $\begin{array}{l}-0.4 \\
\end{array}$ \\
\hline 0.1 & 0.2 & 30 & 106.2 & 106.7 & 0.5 \\
\hline 0.1 & 0.3 & 20 & 106.3 & 107.0 & 0.7 \\
\hline 0.1 & 0.4 & 15 & 106.4 & 107.7 & 1.2 \\
\hline 0.1 & 0.5 & 13 & 106.8 & 108.8 & 1.8 \\
\hline
\end{tabular}

TABLE II. COMPARISON BETWEEN MCRTS AND MODTRAN DERIVED TOA RADIANCE AT ASTER/VNIR BAND 3(810NM)

\begin{tabular}{|c|c|c|c|c|c|}
\hline \multicolumn{2}{|c|}{ Optical Depth } & \multirow{2}{*}{$\begin{array}{l}\text { Visible } \\
\text { Range } \\
(\mathrm{km})\end{array}$} & \multicolumn{2}{|c|}{$\begin{array}{l}\text { TOA Radiance } \\
\left(\mathrm{W} / \mathrm{m}^{2} / \mathrm{str} / \mu \mathrm{m}\right)\end{array}$} & \multirow{2}{*}{$\begin{array}{l}\% \\
\text { difference } \\
\text { between } \\
\text { MCRTS } \\
\text { and } \\
\text { MODTRAN }\end{array}$} \\
\hline Molecule & Aerosol & & MCRTS & MODTRAN & \\
\hline 0.02 & 0.1 & 55 & 144.7 & 145.1 & 0.3 \\
\hline 0.02 & 0.2 & 25 & 141.9 & 143.0 & 0.8 \\
\hline 0.02 & 0.3 & 18 & 139.7 & 141.8 & 1.5 \\
\hline 0.02 & 0.4 & 12 & 137.2 & 140.1 & 2.1 \\
\hline
\end{tabular}

\section{EXPERIEMNTS}

\section{A. Slope Effect}

The effects of geographic feature, slope, and tree shape as well as tree-tree interaction on TOA radiance were investigated. Solar azimuth and zenith angles are set at 17, 58 degrees, respectively. As the atmospheric influence to TOA radiance in $550 \mathrm{~nm}$ is greater than that in $810 \mathrm{~nm}$ so that MCRTS is conducted in the $550 \mathrm{~nm}$.

Forested areas are assumed for the ground surface material together with bare soil and grass fields. Two types of trees, deciduous and coniferous trees are assumed. The different tree shapes, ellipsoidal and cone shaped Lambertian surface, respectively, are assumed for deciduous and coniferous trees. Also geographical feature, slopes are taken into account. Furthermore, two surfaces with area of $25 \mathrm{~km}$ by $50 \mathrm{~km}$ are assumed on the ground in the simulation cell in order to concentrate the mixed pixels that are situated along with the center of the ground. IFOV of sensor is set at $15 \mathrm{~m}$ on the ground. Adjacency effect from the neighboring pixels is investigated with MCS. Through a comparison of the number of photons coming from the IFOV of the pixels that are situated at the center of the ground surface in the simulation cell to that from the IFOV of the neighboring pixels, the adjacency effect is calculated.

Slope effect with the different situation of two different slopes, Slope A and Slope B with the same surface reflectance of 0.3 at $550 \mathrm{~nm}$ is shown in Table 3. Optical depth of aerosol and molecule are 0.35 and 0.14 , respectively. Two different flat surfaces with the different slope that ranges from 0 to 30 degrees with 15 degrees step are assumed. The other parameters are the same mentioned above. In accordance with slope angle, TOA radiance is decreased due to the fact that the number of photons of which multiple reflections on the ground is occurred.

TABLE III. SLOPE EFFECT WITH THE DIFFERENT SITUATION OF TWO DIFFERENT SLOPES, SLOPE A AND SLOPE B WITH THE SAME SURFACE REFLECTANCE OF 0.3 (FLAT LAMBERTIAN SURFACE) AT 550NM (SOLAR AZIMUTH AND ZENITH ANGLES ARE 17 AND 58DEG.)

\begin{tabular}{|l|l|l|l|}
\hline Slope A and B & 0 and 0 & 15 and 0 & 30 and 0 \\
\hline TOA Radiance & 101.19 & 101.00 & 98.62 \\
\hline
\end{tabular}




\section{B. Tree-tree interaction and the effect of tree shape}

Coniferous trees are simplified with cone shape of Lambertian surface while deciduous trees are ellipsoidal shape of Lambertian surface as are shown in Figure 5. These simplified models of trees are aligned with tree distance in the two dimensional ground surface of the simulation cell. By comparing the TOA radiance for the different types of trees, the effect of tree shape (types) is investigated. In the investigation, the number of photons of which multiple reflections among trees are occurred is counted ((d) and (e) in the Figure 6) as a tree-tree interaction.

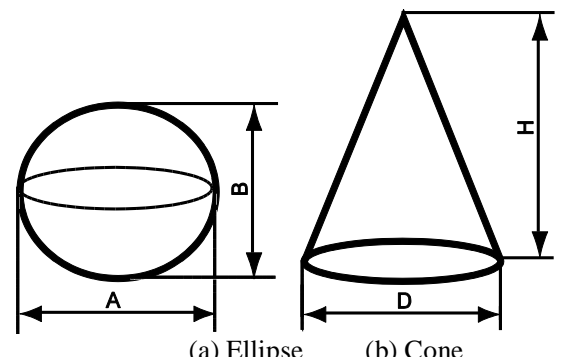

Fig. 5. Two types of trees, (a) ellipsoidal shape of deciduous trees and (b) cone shape of coniferous trees.

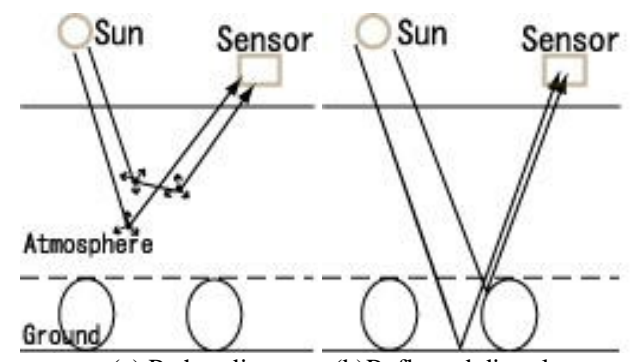

(a) Path radiance (b)Reflected directly

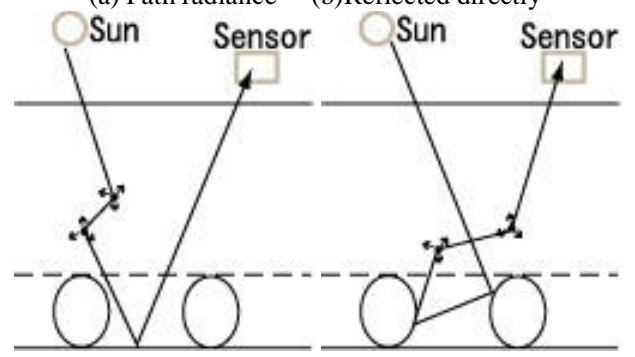

(c) Reflected in the atmosphere (d) Multiple reflections among trees

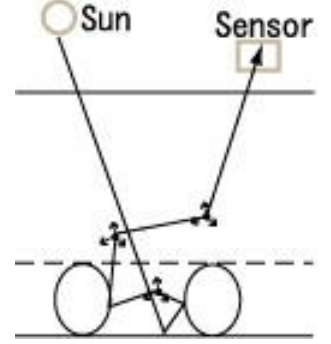

(e) Multiple reflections among trees and ground

Fig. 6. Sun-atmosphere-ground paths (Each tree is treated as each individual ellipse: deciduous or cone: coniferous trees)
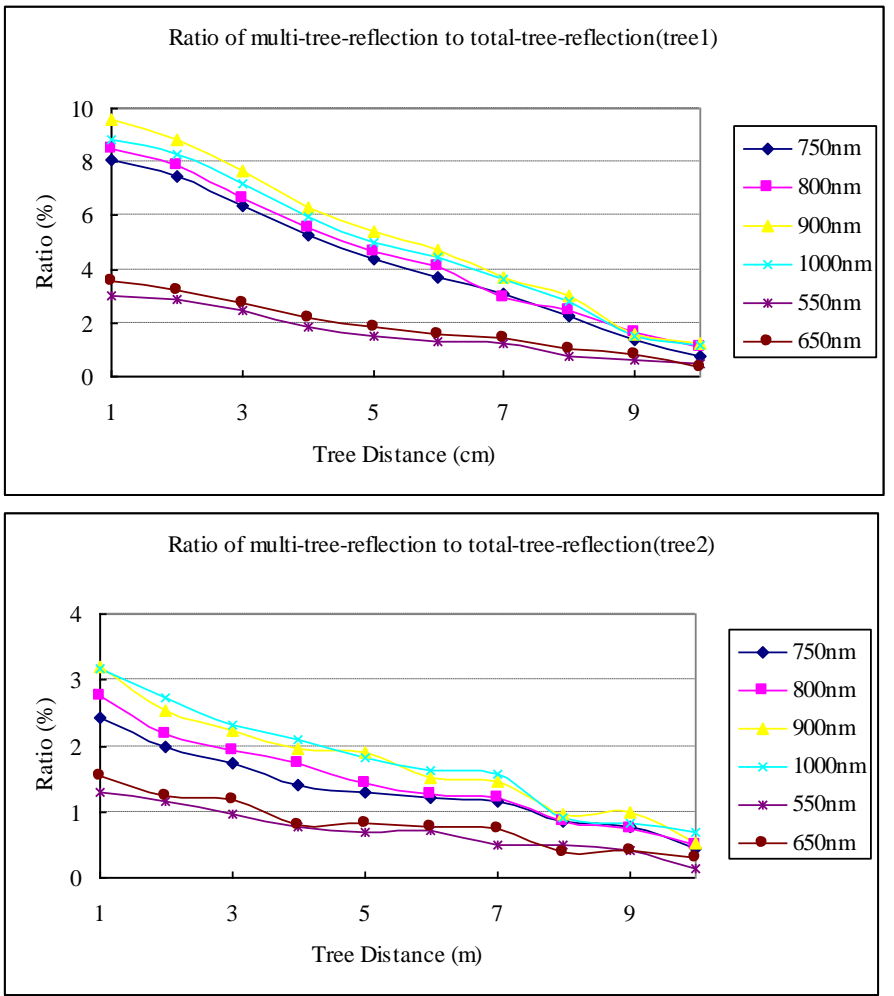

Fig. 7. Percentage ratio of multiple reflections among trees to the total TOA (the Top of the Atmosphere) radiance for deciduous trees (Left) and for coniferous trees (Right)

In the investigation of tree-tree interaction with MCRTS, (Tree 1): $\mathrm{A}=1 \mathrm{~m}, \mathrm{~B}=1 \mathrm{~m}$ of spherical deciduous trees and (Tree 2): $\mathrm{D}=1 \mathrm{~m}, \mathrm{H}=2 \mathrm{~m}$ of cone shaped coniferous trees are assumed and aligned on the ground with tree distance ranges from 1 to $10 \mathrm{~m}$. The ratios of tree-tree interaction to the total TOA radiance are calculated. As are shown in Fig.7, tree-tree interaction of ellipsoidal deciduous trees is greater than that of cone shaped coniferous trees. The former ranges from 3 to $9.5 \%$ depending on the wavelength while the latter ranges from 1.2 to $3.3 \%$. Also it is found that tree-tree interaction decreases in accordance with tree distance.

\section{Interpretation of the mixed pixels in the Terra/ASTER/VNIR imagery data}

In order to validate the proposed nonlinear mixed pixel model and to interpret the mixed pixels, multiple scattering in the atmosphere and geographical feature, shape of the ground cover materials, material-material interaction, experiments are conducted with actual Terra/ASTER/VNIR data of vegetated and forested areas of Saga, Japan, which was acquired at 11:09 on December 15 2004. Weather on that day in Saga is: fair and ground air temperature is 15.7 degree Celsius. Relative humidity is $60 \%$ while atmospheric pressure is $1023.7 \mathrm{hPa}$. Meanwhile, wind direction is East-North-East and wind speed is $5.1 \mathrm{~m} / \mathrm{s}$. A portion of natural color image together with three intensive study areas is shown in Figure 8. 


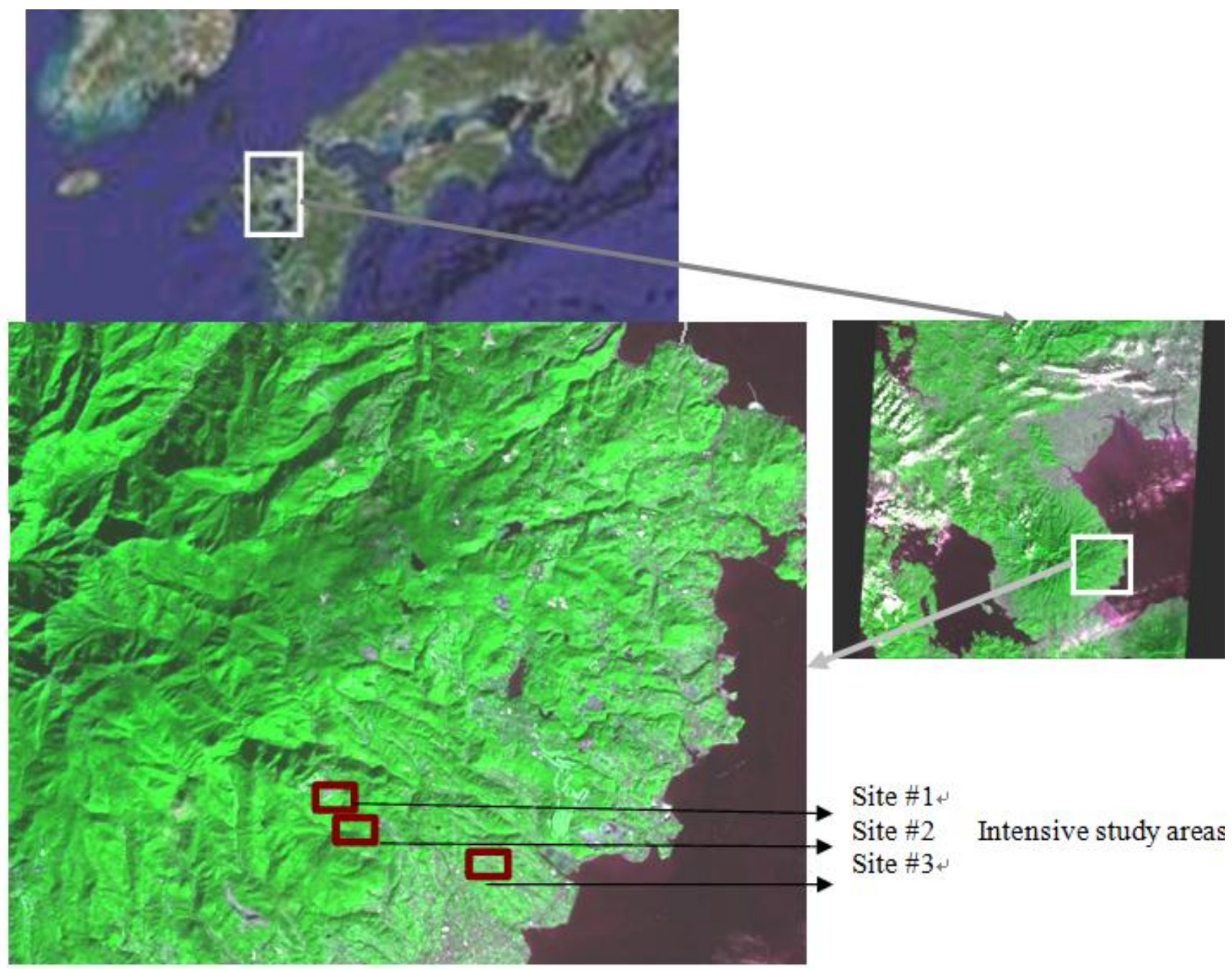

Fig. 8. Terra/ASTER/VNIR image data used and the intensive study areas

Three intensive study areas are situated at Ochiaigawa and the surrounding areas of Korai-cho in Nagasaki prefecture, Japan. The latitude and longitude of the centre location is as follows, Site1: $\left(32^{\circ} 57.30 \mathrm{~N}, 130^{\circ} 7.19 \mathrm{E}\right)$, Site2: $\left(32^{\circ} 56.33 \mathrm{~N}\right.$, 130 $7.25 \mathrm{E})$ and Site3: $\left(32^{\circ} 56.13 \mathrm{~N}, 130^{\circ} 10.21 \mathrm{E}\right)$.

Solar azimuth and zenith angles are 17 and 58 degrees, respectively. Figure 9 shows geographical feature and ground cover materials of the site \#1, \#2 and \#3 while Figure 10 shows topographic maps and a portion of VNIR image including mixed pixels of the site \#1, \#2 and \#3. The slopes and the ground cover materials of the test sites are known. Optical depth of aerosol, molecule, ozone and water vapor at the wavelength of $550 \mathrm{~nm}$ were $0.35,0.14,0.009,0.001$, respectively so that optical depth of ozone and water vapor are negligible in the MCRTS while optical depth of aerosol and molecule at $810 \mathrm{~nm}$ are 0.16 and 0.02 , respectively and the other influencing factors are also negligible.
The detailed parameters for the site \#1, \#2 and \#3 are shown in Table 4. Table 5 shows the experimental results of ASTER/VNIR derived at sensor radiance, MCRTS derived TOA radiance with the proposed nonlinear and linear mixed pixel models. TOA radiance of the mixed pixels of the site \#1, \#2, \#3 is estimated with MCRTS assuming two homogeneous sloped ground surfaces with the different materials and with the same area of $25 \mathrm{~km}$ by $50 \mathrm{~km}$. Two dimensionally aligned $\mathrm{A}=1 \mathrm{~m}, \mathrm{~B}=1 \mathrm{~m}, \mathrm{~d}=2 \mathrm{~m}$ of deciduous trees with surface grass (the reflectance are same as paddy field) is assumed for surface A of the site \#1 and \#3 while two dimensionally aligned $D=1 \mathrm{~m}$, $\mathrm{H}=2 \mathrm{~m}, \mathrm{~d}=2 \mathrm{~m}$ of coniferous trees with the same surface grass mentioned above is assumed for surface B of the site \#1 \#2. Flat surface is assumed for bare soil and paddy field for surface A of the site \#2 and surface B of the site \#3. It is not easy to simulate the real situation ground surface materials so that only the mixed pixel is concentrated for interpretation 


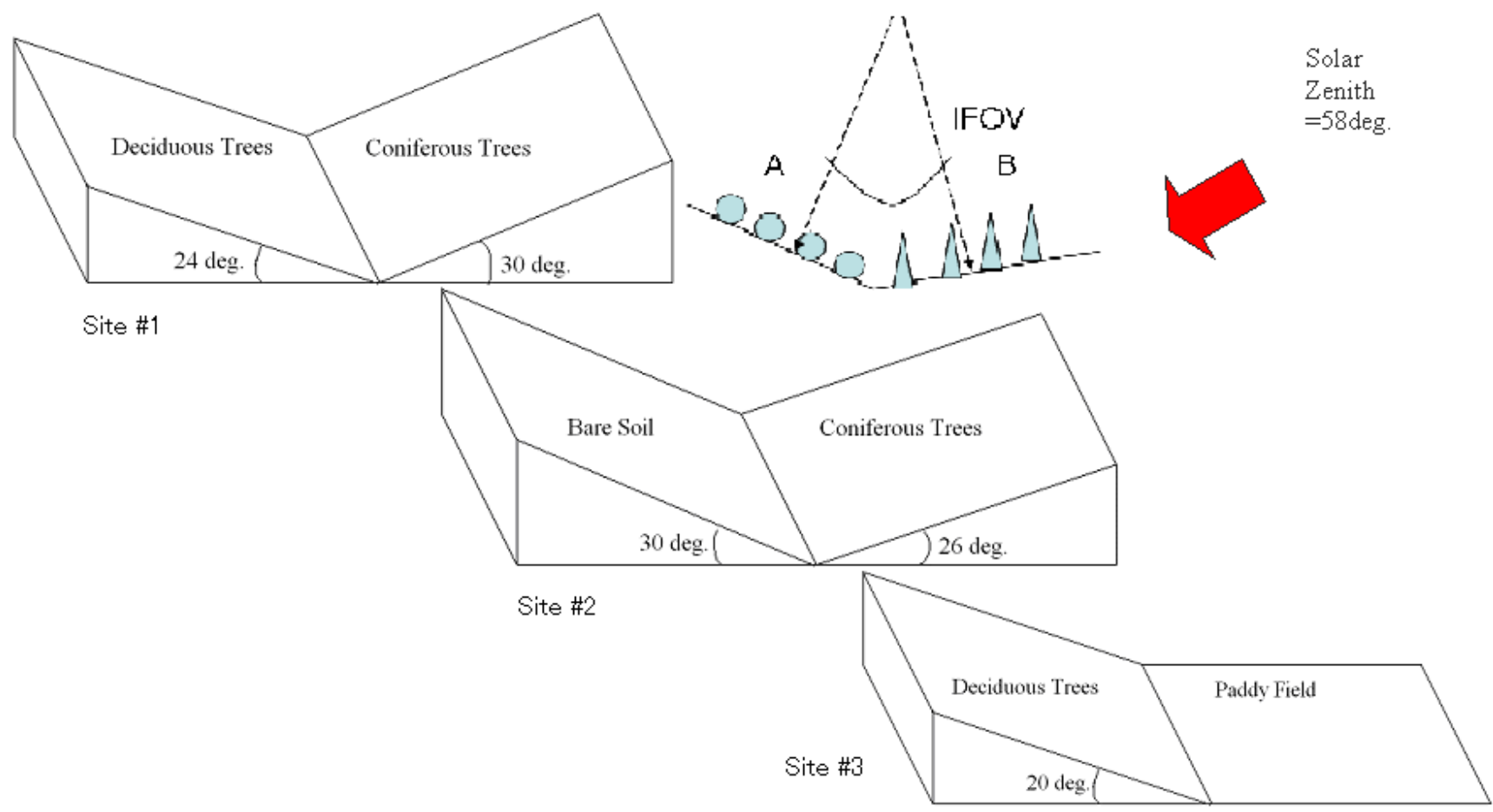

Fig. 9. Geographical features and ground cover types of the site 1,2 and 3.

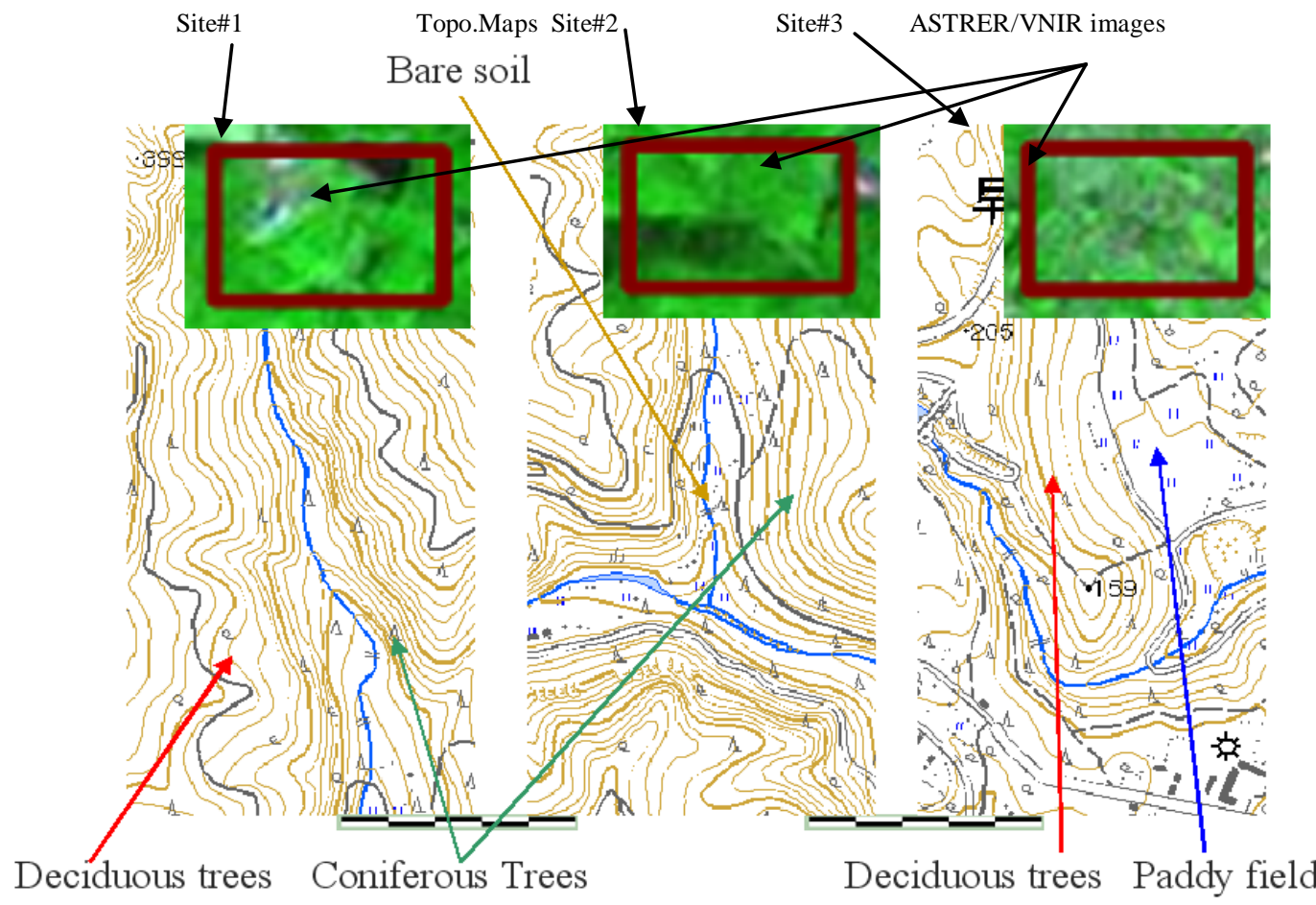

Fig. 10. Portion of ASTER/VNIR images of the intensive study areas of site \#1, \#2, and \#3 including mixed pixels and the corresponding topographical maps. 
TABLE IV. ANGLES OF THE SLOPES, GROUND COVER MATERIALS, REFLECTANCE AND OPTICAL DEPTH OF AEROSOL AND MOLECULE OF THE SITE \#1, \#2 AND \#3 ( $\Gamma_{\text {AX }}$ DENOTES REFLECTANCE AT X NM OF WAVELENGTH).

\begin{tabular}{|l|l|l|l|}
\hline & Site \#1 & Site \#2 & Site \#3 \\
\hline Slope $\alpha$ & $\begin{array}{l}24 \quad \text { deg. } \\
\text { (Deciduous) }\end{array}$ & $\begin{array}{l}30 \text { deg. (Bare } \\
\text { soil) }\end{array}$ & $\begin{array}{l}20 \text { deg. } \\
\text { (Deciduous) }\end{array}$ \\
\hline Slope $\beta$ & $\begin{array}{l}28 \text { deg. } \\
\text { (Coniferous) }\end{array}$ & $\begin{array}{l}26 \text { deg. } \\
\text { (Coniferous) }\end{array}$ & deg. (Paddy) \\
\hline $\begin{array}{l}\text { Reflectance } \Gamma_{\text {A550, }} \\
\Gamma_{\text {A810 }}\end{array}$ & $0.14,0.52$ & $0.20,0.13$ & $0.14,0.52$ \\
\hline $\begin{array}{l}\text { Reflectance } \Gamma_{\text {B550, }} \\
\Gamma_{\text {B810 }}\end{array}$ & $0.08,0.42$ & $0.08,0.48$ & $0.12,0.11$ \\
\hline
\end{tabular}

TABLE V. COMPARISON BETWEEN ASTER/VNIR DERIVED RADIANCE (W/M $\left.{ }^{2} / \mathrm{STR} / \mathrm{MM}\right)$, ESTIMATED RADIANCE BASED ON LINEAR AND NONLINEAR MIXTURE MODELS

\begin{tabular}{|l|l|l|l|}
\hline & Site \#1 & Site \#2 & Site \#3 \\
\hline ASTER/VNIR (Band1, Band3) & $104.9,144.7$ & $105.9,138.2$ & $104.1,137.6$ \\
\hline Linear (Band1, Band3) & $104.7,138.2$ & $106.7,139.6$ & $106.0,136.9$ \\
\hline Nonlinear (Band1, Band3) & $109.5,141.1$ & $111.3,142.2$ & $110.4,141.9$ \\
\hline
\end{tabular}

Table 6 shows a comparison of estimated reflectance of the mixed pixels based on linear and nonlinear mixed pixel models and the percent difference between both. It seems that the estimated radiance based on linear mixed pixel model is much closer than those for nonlinear mixed pixel model.

The ASTER/VNIR derived radiance is calculated based on onboard calibration data. There is approximately $10 \%$ of discrepancy between onboard calibration data and vicarious calibration data for band 1 while that for the band 3 is around $3 \%$. Thus if the vicarious calibration is more reliable than onboard calibration, then the VNIR derived at sensor radiance of band 1 would be 115.4, 116.5, 114.5 for the site 1,2 and 3, respectively while those for band 3 are 108.0, 109.1 107.2 so that the estimated TOA radiance based on nonlinear mixture model is much closer than those for linear mixed pixel model except for the Site3.

It seems that the site 3 consists of flat paddy and $20 \mathrm{deg}$. sloped deciduous trees so that not so significant tree-tree interaction and slope effect are occurred. TOA or at sensor radiance are estimated so that the surface reflectance can be derived because up/down-ward radiance on the ground can be estimated. The estimated reflectance of the mixed pixels together with the percent difference between the estimated reflectance based on linear and nonlinear mixture models are shown in Table 5.

The percent difference ranges from about 2 to $10 \%$. In the linear mixture model, TOA radiance of the mixed pixel is expressed with linear combination of plural material (reflectance and mixing ratio). It may conclude that apparent estimated reflectance of the surface material may be different from the actual reflectance with 2 to $10 \%$ depending on reflectance and shape of the surface materials and geographical feature, slope and roughness.
TABLE VI. COMPARISON OF ESTIMATED REFLECTANCE OF THE MIXED PIXELS BASED ON LINEAR AND NONLINEAR MIXTURE MODELS AND THE PERCENT DIFFERENCE BETWEEN BOTH

\begin{tabular}{|l|l|l|c|}
\hline & Linear & Nonlinear & $\begin{array}{l}\% \\
\text { between both }\end{array}$ \\
\hline $\begin{array}{l}\text { Site \#1 (Band1, } \\
\text { Band3) }\end{array}$ & $0.161,0.451$ & $0.168,0.459$ & $4.08,1.83$ \\
\hline $\begin{array}{l}\text { Site \#2 (Band1, } \\
\text { Band3) }\end{array}$ & $0.201,0.314$ & $0.221,0.342$ & $9.95,8.92$ \\
\hline $\begin{array}{l}\text { Site \#3 (Band1, } \\
\text { Band3) }\end{array}$ & $0.210,0302$ & $0.217,0.308$ & $3.38,2.08$ \\
\hline
\end{tabular}

\section{Adjacency effect}

Actual surface situations are different from the assumed surface situation of MCRTS. Although there are a variety of pixels with the different materials surrounding at the mixed pixel in concern, just two homogeneous surfaces with $25 \mathrm{~km}$ by $50 \mathrm{~km}$ area is assumed in the MCRTS. The number of photons coming out from the top of the atmosphere through the IFOV (15m on the ground) is counted for calculation of TOA radiance of the mixed pixels that situates at the border between two surfaces.

In order to investigate the influences due to the surrounding pixels, a different reflectance $\left(\Gamma_{\mathrm{A}} \pm 10 \%, \Gamma_{\mathrm{B}} \pm 10 \%\right)$ of neighboring pixels are considered. Namely, the rest of areas of "a" and "b", $24.925 \mathrm{~km}$ by $50 \mathrm{~km}$ in Figure 1 is filled up with $\pm 10 \%$ different reflectance of materials for surface " $A$ " and "B", respectively. TOA radiance of the mixed pixels is then affected by the surrounding pixels (it is called adjacency effect).

Adjacency effect of band1 is greater than band 3. The result of adjacency effect estimated with MCRTS for band 1 is shown in Table 7. The effect depends on reflectance, slope, and shape of ground materials of the neighboring pixels as well as optical depth of the atmosphere. As it is mentioned before, interaction between ground cover materials depends on the reflectance, shape of the materials and slope. Adjacency effect of site \#2 is expected to be the largest followed by site $\# 1$ and \#3. The results show almost same expected order except site \#3. Contribution of reflectance to the adjacency effect seems to be greater than slope. It is found that the effect is within the range of a couple of percent.

TABLE VII. ADJACENCY EFFECT OF THE NEIGHBORING PIXELS WITH $\pm 10 \%$ DIFFERENT REFLECTANCE TO THE TOA RADIANCE OF THE MIXED PIXELS ESTIMATED WITH MCS AT 550NM: TOP TWO COLUMN AND AT 810NM: BOTTOM TWO COLUMN (OPTICAL DEPTH OF MOLECULE AND AEROSOL ARE 0.35, 0.14, RESPECTIVELY.)

\begin{tabular}{|c|c|c|c|c|c|c|c|c|c|}
\hline \multirow[t]{2}{*}{$\begin{array}{l}\text { Slope, } \\
\text { Reflectance }\end{array}$} & \multicolumn{3}{|c|}{$\begin{array}{l}\text { Site \#1: } \\
0.14 / 0.08\end{array}$} & \multicolumn{3}{|c|}{$\begin{array}{l}\text { Site \#2: } 30 / 26 \text {, } \\
0.20 / 0.08\end{array}$} & \multicolumn{3}{|c|}{$\begin{array}{l}\text { Site \#3: } \quad 20 / 0, \\
0.14 / 0.12\end{array}$} \\
\hline & $-10 \%$ & $0 \%$ & $+10 \%$ & $-10 \%$ & $0 \%$ & $+10 \%$ & $-10 \%$ & $0 \%$ & $+10 \%$ \\
\hline Adjacency & 109.21 & 109.5 & 111.80 & 108.46 & 111.3 & 114.2 & 107.90 & 110.4 & 112.83 \\
\hline$\%$ Ratio & -2.09 & 0 & +2.10 & -2.56 & 0 & +2.61 & -2.26 & 0 & +2.21 \\
\hline Adjacency & 137.8 & 141.1 & 144.3 & 138.4 & 142.2 & 146.1 & 139.0 & 141.9 & 144.9 \\
\hline$\%$ Ratio & -2.32 & 0 & +2.29 & -2.66 & 0 & +2.73 & -2.04 & 0 & +2.14 \\
\hline
\end{tabular}




\section{CONCLUSION}

It is found that the influence due to tree-tree interaction on the surface reflectance estimation depends on tree distance and ranges from 8 to $10 \%$. Also it is found that the estimated surface reflectance based on the proposed nonlinear mixed pixel model is much closer to that from linear mixed pixel model. It may conclude that influence due to multiple reflections among ground cover targets has to be considered on the surface reflectance estimation.

Through the comparison between the estimated reflectance derived from the actual ASTER/VNIR of the mixed pixels and the estimated reflectance based on the linear and the proposed nonlinear mixture models shows the discrepancy ranges from about 2 to $10 \%$. Also it is found that the estimated reflectance based on the nonlinear model is much closer than that of the linear model.

Adjacency effect on TOA radiance of the mixed pixels is highly dependent on reflectance of materials followed by slope and shape of the materials. Adjacency effect from the surrounding pixels with $10 \%$ different reflectance is within $3 \%$ so that 2 to $10 \%$ of the difference between apparent and real reflectance exists with $3 \%$ of possible error. Real situation is more complicated and is not easy to simulate.

\section{ACKNOWLEDGMENT}

The author would like to thank Mr. Kohei Imaoka for his efforts through experiments and simulations.

\section{REFERENCES}

[1] Arai, K, Lecture Notes on Remote Sensing, Morikita-Shuppan, Co.Ltd., 2005
[2] C.C.Borel and S.A.Gerst, Nonlinear spectral mixing models for vegetative and soils surface, Remote Sensing of the Environment, 47, 2, 403-416, 1994.

[3] R.N.Clark and T.I.Roush, Reflectance spectroscopy: Quantitative analysis techniques for remote sensing applications, Journal of Geophysical Research, 89, B7, 6329-6340, 1984.

[4] B.Hapke, Bidirection reflectance spectroscopy, I. Theory, Journal of Geophysical Research, 86, 3039-3054, 1981.

[5] Mersenne Twister (MT), http://www.math.sci.hiroshima-u.ac.jp/ mmat/MT/mt.html

[6] B.Nash and J.Conel, Spectral reflectance systematic for mixtures of powered hypersthenes, labradoride and ilmenite, Journal of Geophysical Research, 79, 1615-1621, 1974.

[7] R.Singer, Near infrared spectral reflectance of mineral mixtures: Systematic combinations of pyroxenes olivine and iron oxides, Journal of Geophysical Research, 86, 7967-7982, 1974.

[8] R.Singer and T.B.McCord, Mars; Large scale mixing of bright and dark surface materials and implications for analysis of spectral reflectance, Proc., 10th Lunar and Planetary Sci., Conf., 1835-1848, 1979.

\section{AUTHORS PROFILE}

Kohei Arai, He received BS, MS and PhD degrees in 1972, 1974 and 1982, respectively. He was with The Institute for Industrial Science and Technology of the University of Tokyo from April 1974 to December 1978 also was with National Space Development Agency of Japan from January, 1979 to March, 1990. During from 1985 to 1987, he was with Canada Centre for Remote Sensing as a Post Doctoral Fellow of National Science and Engineering Research Council of Canada. He moved to Saga University as a Professor in Department of Information Science on April 1990. He was a councilor for the Aeronautics and Space related to the Technology Committee of the Ministry of Science and Technology during from 1998 to 2000 . He was a councilor of Saga University for 2002 and 2003. He also was an executive councilor for the Remote Sensing Society of Japan for 2003 to 2005 . He is an Adjunct Professor of University of Arizona, USA since 1998. He also is Vice Chairman of the Commission "A" of ICSU/COSPAR since 2008. He wrote 30 books and published 322 journal papers 